$16^{\text {th }}$ International Conference on

AEROSPACE SCIENCES \& AVIATION TECHNOLOGY,

ASAT - 16 - May 26 - 28, 2015, E-Mail: asat@ mtc.edu.eg

Military Technical College, Kobry Elkobbah, Cairo, Egypt

Tel : +(202) 24025292 - 24036138, Fax: +(202) 22621908

\title{
COMPARATIVE STUDY BETWEEN DIFFERENT FILLERS USED AS REINFORCEMENTS OF RUBBER THERMAL INSULATORS
}

\author{
El-Dakhakhny A. M. ${ }^{*}$, Ahmed A. F.** ${ }^{* *}$ El- Marsafy S. ${ }^{\dagger}$, and Abadeer E. ${ }^{\dagger}$
}

\begin{abstract}
Solid rocket motors typically include an outer case or shell that houses solid propellant grains. Internal insulation in a solid rocket motor is a layer of heat-barrier material placed between the internal surface of the case and the propellant which. The aim of the present study is to develop and characterize an asbestos-free rubber for use as rocket motor insulator which needs to be taken into account for protecting in the planning of space missions, in their design, and in their operation. Such insulation is based on aramid fiber in the pulp form, alumina and/or silica aerosol as reinforcement for Ethylene Propylene Diene Monomer (EPDM). Different formulations based on these fillers were prepared. The fillers dispersed in the EPDM polymeric matrix to obtain a homogenous master batch for curing. The physical, mechanical (density, hardness, tensile strength and elongation) and thermal properties (effective thermal conductivity) of different compositions were obtained. The ablation resistance of samples with different compositions was measured. Thermo-gravimetric analyses versus reinforcement content were obtained. The effect of changing aramid fiber in the pulp form, alumina and/or silica aerosol volume fractions was studied. For application for solid rocket motor insulation, Reinforcement of EPDM with KP improves the performance of the material with respect to mechanical properties and thermal properties ( thermal conductivity) while not improving well the performance with respect to ablation resistance. Using hybrid reinforcement content $(\mathrm{KP}+\mathrm{Al}+\mathrm{Si})$ inside EPDM improves the performance of EPDM with respect to mechanical properties, thermal properties, ablation resistance and decomposition resistance. The best volume fraction which gives the best performance of the insulation material is $10 \mathrm{Phr} \mathrm{KP}+5 \mathrm{Phr} \mathrm{Al}+5 \mathrm{Phr} \mathrm{Si}$. A new type of insulation material using the hybrid reinforcements was developed for the first time.
\end{abstract}

KEYWORDS: Thermal insulator, Fillers, Solid rocket motor

\footnotetext{
* PhD student, Egyptian Armed Forces

** Egyptian Armed Forces

$\uparrow$ Professor Doctor, Faculty Of Engineering, Cairo University

+ Professor Doctor, Faculty Of Engineering, Cairo University
} 


\section{INTRODUCTION}

Solid rocket motors typically include an outer case or shell that houses solid propellant grains. The rocket motor case is conventionally manufactured from a rigid, yet durable, material such as steel or filament-wound composite. The propellant is housed within the case and is formulated from a composition designed to undergo combustion and thereby produces the requisite thrust for attaining rocket motor propulsion [1-2]. Internal insulation in a solid rocket motor is a layer of heat-barrier material placed between the internal surface of the case and the propellant [3]. The primary function of internal insulation is to prevent the rocket motor case from reaching temperatures that may endanger its structural integrity. Temperatures inside the rocket motor case typically reach $2,760^{\circ} \mathrm{C}\left(5,000^{\circ} \mathrm{F}\right)$, and interior pressures may exceed $10.35 \mathrm{MPa}$ (1500 psi). These factors combine to create a high degree of turbulence within the rocket motor case. In addition, particles are typically entrained in the gases produced during propellant combustion. Under the turbulent environment, these entrained particles can erode the rocket motor insulation. If the insulating layer and liner are pierced during rocket motor operation, the casing is susceptible to melting or degradation, which can result in failure of the rocket motor. Thus, it is crucial that insulation compositions withstand the extreme conditions experienced during propellant combustion and protect the case from the burning propellant.

The currently used insulators have deficiency in at least one of the primary requirements of the insulator material [4-9]. Reinforced thermosets, crack and/or blister as a result of the rapid temperature and pressure fluctuations experienced during combustion. Although phenolic based insulation are much more erosion resistant than many insulators which is due to the strong char formed during decomposition, it does not exhibit high strain capability and cannot survive high aeroheating loads. For elastomers filled with carbon black the ablation resistance of the whole insulation is inadequate to withstand the high stresses and erosion rates resulting from the combustion gases. In addition the current International Agency for Research on Cancer (IARC) evaluates that Carbon black is possibly carcinogenic to humans. Also, for the insulators based on elastomers filled with asbestos the mechanical properties and the ablation resistance of the whole insulation are adequate to withstand the high stresses and erosion rates resulting from the combustion gases. However asbestos is prevented from use due to its health hazards.

Reinforced rubbers are usually used as rocket motor insulators [10-13]. One such insulation uses asbestos fibers as reinforcement for Ethylene Propylene Diene Monomer (EPDM). EPDM is peroxide cured (PCA) and contains antimony trioxide, dechlorane $+\mathrm{R}$ as flame retardant agents [14-20].

The aim of the present study is to develop and characterize an asbestos-free rubber for use as rocket motor insulator which need to be taken into account for protecting in the planning of space missions, in their design, and in their operation.. The insulators are based on aramid fiber in the pulp form (Kevlar), Alumina and/or Silica aerosil fillers for Ethylene Propylene Diene Monomer (EPDM).

\section{METHODOLOGY}

Different formulations of the selected reinforcements with EPDM polymer were prepared to investigate the physical, mechanical, thermal and ablative properties. The formulations were mixed using a two roll mill to attain uniform dispersion of the reinforcement inside EPDM. The formulations were cured under a press $\left(\mathrm{T}=170{ }^{\circ} \mathrm{C}, \mathrm{P}=28\right.$ tons $)$ using compression 
molding. Sheets with different dimensions were made for investigation of the physical, mechanical, thermal and ablative properties [21-23].

Different formulations (5 samples) of Kevlar pulp (12- $20 \mathrm{Phr}$ ) with EPDM polymer were prepared. All the formulations contain $100 \mathrm{Phr}$ EPDM, $40 \mathrm{Phr}$ dechlorane, $20 \mathrm{Phr}$ antimony trioxide and $3 \mathrm{Phr}$ PCA. The same procedure is followed to prepare samples of similar formulations with the only exception being the type of thermal insulant. Samples from 6 to 10 are loaded with Kevlar pulp and Alumina, while those from 11 to 15 are loaded with Kevlar and silica and samples from 16 to 20 are loaded with Kevlar, Alumina and Silica, in different proportions, as indicated in Table (1).

Every time the type of insulant is changed, the curing molds were cleaned and prepared for curing where Teflon based release agent was applied with the same size of the samples $(300 \mathrm{x}$ $150 \mathrm{~mm}$ ), prepared and placed between the mold parts and the material for releasing and easily demolding after curing.

\section{EXPERIMENTAL WORK}

Density

The density of any prepared formulations is an essential property because it judges the accurate content of all ingredients in the prepared samples. The Sartorius analytical balance (made in Germany) was used in evaluating the density of all prepared formulations in this work according to the standard technique.

Tensile Strength and Elongation

MTS machine was used for the determination of the tensile strength and elongation of vulcanized rubber according to ASTM D 412-92.

\section{Hardness}

The test method for measuring shore A hardness for insulation sheet describes a procedure for measuring the hardness of rubber. The hardness was obtained by the difference in penetration depth of a ball with specified dimension under two conditions of contact with the rubber, with a small initial force and with a much larger final force. The differential penetration was taken at a specified time and converted to a hardness scale value according to ASTM: D2240-91.

\section{Thermal Conductivity}

To measure the thermal conductivity $\mathrm{K}$ of the cured thermal insulation compositions, the comparative thermal conductivity instrument is used where the thermal conductivity of the unknown specimen is determined by comparing this property to the known thermal conductivity of a reference material. The reference material is chosen to match, as closely as possible, the expected thermal conductance of the unknown sample.

TGA

Another important aspect of the characterization of the material compositions includes defining the primary reactions in the decomposition of the material. TGA (Thermo gravimetric analysis) is a very useful tool in establishing the primary reactions that occur [24- 
26]. Thermo gravimetric Analyzer (TGA) is a thermal weight-change analysis instrument, used in conjunction with a TA Instruments thermal analysis controller and associated software, to make up a thermal analysis system. The Thermo gravimetric Analyzer measures the amount and rate of weight change in a material, either as a function of increasing temperature, or isothermally as a function of time, in a controlled atmosphere. It can be used to characterize any material that exhibits a weight change and to detect phase changes due to decomposition, oxidation, or dehydration. This information helps the scientist or engineer identify the percent weight change and correlate chemical structure, processing, and end-use performance.

\section{Ablation}

Another important aspect of the characterization of the material compositions includes measurement of ablation rate according to ASTM-E-285-80. The ablation test was done by preparing a sample of the insulation material with $3 \mathrm{~mm}$ thickness, length $20 \mathrm{~cm}$ and width 20 $\mathrm{cm}$. Then it bonded to a steel piece with the same dimensions with the special adhesive Epon 828 and Epicure. A thermocouple is then fixed in the back of steel sheet and the insulation material is exposed to a high temperature torch $\left(2010^{\circ} \mathrm{C}\right)$. The sample characteristics before and after the test are recorded.

\section{RESULTS AND DISCUSSIONS}

\section{Density}

In Density test, it was found that density increases with increasing KP content in EPDM as shown in Fig(9). This is because of the higher density of $\mathrm{KP}\left(1.44 \mathrm{~g} / \mathrm{cm}^{3}\right)$ as compared to $\operatorname{EPDM}\left(0.86 \mathrm{~g} / \mathrm{cm}^{3}\right)$. Density decreases with decreasing KP content and increasing Al content as shown in Fig(10). This is because of the low density of $\mathrm{Al}\left(1.3 \mathrm{~g} / \mathrm{cm}^{3}\right)$ as compared to $\mathrm{KP}$ $\left(1.44 \mathrm{~g} / \mathrm{cm}^{3}\right)$. Density decreases with decreasing KP content and increasing Si content in EPDM as shown in Fig(11). This is because of the very low density of Si $\left(0.05 \mathrm{~g} / \mathrm{cm}^{3}\right)$ compared to KP $\left(1.44 \mathrm{~g} / \mathrm{cm}^{3}\right)$. Density increases by increasing KP content inside the hybrid (decreasing $\mathrm{Al}$ and $\mathrm{Si} \mathrm{Phr}$ content) as shown in Fig(12). This is because of the higher density of $\mathrm{KP}\left(1.44 \mathrm{~g} / \mathrm{cm}^{3}\right)$ compared to $\mathrm{Al}$ and $\mathrm{Si}\left(1.3\right.$ and $\left.0.05 \mathrm{~g} / \mathrm{cm}^{3}\right)$.

\section{Tensile Strength and Elongation}

Increasing Phr content of KP in EPDM increases the tensile strength of the material, while elongation decreases and this is due to the classification of Kevlar as a very good reinforcement filler and its very highly tensile strength characterization (see Fig(1)). Decreasing $\mathrm{Phr}$ content of KP and increasing Phr of Al in EPDM will decrease the tensile strength of the material while elongation increase this is due to the poor tensile characteristics of Alumina compared to that of Kevlar as shown in Fig(2). Decreasing Phr content of KP and increasing $\mathrm{Phr}$ of $\mathrm{Si}$ in EPDM will decrease the tensile strength of the material while elongation increase this is because $\mathrm{Si}$ tensile characteristics dominate on the highly tensile characteristics of KP as shown in Fig(3). Increasing Phr content of KP and decreasing Phr content of $\mathrm{Al}$ and $\mathrm{Si}$ in EPDM inside the hybrid will increase the tensile strength of the material. This is due to the very high surface area of KP and its high tensile characteristics, meanwhile, the elongation will decrease with decreasing the $\mathrm{Al}$ and $\mathrm{Si} \mathrm{Phr}$ content inside the hybrid (increasing KP Phr content) as shown in Fig(4). 


\section{Hardness}

It is clear that Hardness increases with increasing KP content in EPDM, and this is due to the shape of KP which is fibers with highly tensile properties as shown in Fig(5). From sample (6) to (10) Hardness decrease with decreasing KP content and increasing Al content in EPDM and this is due to the decrease in the tensile strength as shown in Fig(6). Also from sample (11) to (15) Hardness decreases with decreasing KP content and increasing Si content in EPDM (see Fig(7)) and this is due to the decrease in the tensile strength. But from sample(16) to (20) Hardness increases with increasing KP content inside the hybrid (decreasing $\mathrm{Al}$ and Si Phr content) as shown in Fig(8).

\section{Thermal Conductivity}

It is obvious that increasing KP Phr content in the material will result in decreasing the thermal conductivity of the material as shown in Fig(13). This is due to the lower thermal conductivity of $\mathrm{KP}(0.04 \mathrm{~W} / \mathrm{m} . \mathrm{k})$ compared to EPDM $\left(0.36 \mathrm{~W} / \mathrm{m}^{\circ} \mathrm{C}\right)$. This goes with the requirement of the insulation material to have a very low thermal conductivity. It appears that decreasing $\mathrm{KP} \mathrm{Phr}$ content and increasing $\mathrm{Al} \mathrm{Phr}$ content in the material will result in increasing its thermal conductivity as shown in Fig(14). This is due to the lower thermal conductivity of $\mathrm{KP}(0.04 \mathrm{~W} / \mathrm{m} . \mathrm{K})$ as compared to $\mathrm{Al}(0.3 \mathrm{~W} / \mathrm{m} . \mathrm{K})$. It appears that decreasing $\mathrm{KP} \mathrm{Phr}$ content and increasing Si Phr content in the material will result in increasing its thermal conductivity as shown in Fig(15). This is due to the lower thermal conductivity of KP $(0.04 \mathrm{~W} / \mathrm{m} . \mathrm{K})$ as compared to $\mathrm{Si}(1.3 \mathrm{~W} / \mathrm{m} . \mathrm{K})$. It appears that increasing KP content inside the hybrid and decreasing $\mathrm{Al}$ and $\mathrm{Si}$ phr content will result in decreasing the thermal conductivity of the material as shown in Fig(16). This is due to the low thermal conductivity of KP (0.04 $\mathrm{W} / \mathrm{m} . \mathrm{K})$ compared to $\mathrm{Al}$ and $\mathrm{Si}(0.3$ and $1.3 \mathrm{~W} / \mathrm{m} . \mathrm{K}$ respectively).

\section{TGA}

The resultant TGA curves which relate the weight $\%$ for every insulation composition sample with temperature for $12 \mathrm{Phr} \mathrm{KP}$ and $20 \mathrm{Phr} \mathrm{KP}$ based samples [samples (1), (5)] as shown in Fig (17). The TGA tests indicate for all compositions that an initial decomposition temperature for EPDM (matrix) occurs around $410{ }^{\circ} \mathrm{C}$ and the final decomposition is at $547{ }^{\circ} \mathrm{C}$ where EPDM decomposes to carbonaceous residue of carbon. These provide a net effect of strong carbon based char which is highly erosion resistant. Also the tests indicate that an initial decomposition temperature for flame retardant agent occurs around $575{ }^{\circ} \mathrm{C}$ and the final decomposition is at $722{ }^{\circ} \mathrm{C}$. The only stable ingredient above $1000{ }^{\circ} \mathrm{C}$ is the remaining char from $\mathrm{KP}$ which is stable up to $1430^{\circ} \mathrm{C}$, in addition to the carbon based char remains from decomposition of EPDM.

The TGA analysis for the matrix (EPDM) alone was done as shown in Figure (18). It is evident that the initial decomposition temperature for EPDM is $401{ }^{\circ} \mathrm{C}$ and the final decomposition temperature for EPDM is $496{ }^{\circ} \mathrm{C}$. These temperatures are lower than those obtained from TGA of the whole insulation because KP works as an active shield for EPDM against decomposition.

So as the Phr of KP increases inside EPDM the insulation efficiency increases with respect to decomposition. This is clear where the remaining weight for sample 1 insulation composition is $3.963 \%$ of the total insulation weight while for sample (5) insulation composition is 5.324 $\%$ of the total insulation weight. 
The resultant TGA curves which relate the weight $\%$ for every insulation composition sample with temperature for samples [samples (6), (10)] as shown in Fig (19). The stable ingredients above $1000{ }^{\circ} \mathrm{C}$ are the remaining char from $\mathrm{KP}$ and the remaining of $\mathrm{Al}$ which have a very highly decomposition temperature which is stable up to $2000^{\circ} \mathrm{C}$, in addition to the carbon based char remains from decomposition of EPDM, So as the Phr of KP decreases inside EPDM and the $\mathrm{Phr}$ of $\mathrm{Al}$ increases insulation efficiency increases with respect to decomposition. This is clear where the remaining weight for sample (6) insulation composition is $8.258 \%$ of the total insulation weight while for sample (10) insulation composition is $10.43 \%$ of the total insulation weight.

The resultant TGA curves which relate the weight $\%$ for every insulation composition sample with temperature for samples [samples (11), (15)] as shown in Fig (20)..The stable ingredients above $1000{ }^{\circ} \mathrm{C}$ are the remaining char from KP and the remaining of SI which have a highly synergistic effect and can stand up till $1665^{\circ} \mathrm{C}$, in addition to the carbon based char remains from decomposition of EPDM, So as the Phr of KP decreases inside EPDM and the Phr of SI increases, insulation efficiency increases with respect to decomposition. This is clear where the remaining weight for sample (11) insulation composition is $10.06 \%$ of the total insulation weight while for sample (15) insulation composition is $11.28 \%$ of the total insulation weight.

The resultant TGA curve which relates the weight $\%$ with temperature for samples [samples (16), (20)] as shown in Fig (21). The stable ingredients above $1000{ }^{\circ} \mathrm{C}$ are the remaining char from $\mathrm{KP}$ and the remaining of $\mathrm{AL}$ due to its highly decomposition temperature also the remaining of SI due to its synergetic effect which have a highly synergistic effect, in addition to the carbon based char remains from decomposition of EPDM, So as the Phr of KP increases inside EPDM and the Phr of $\mathrm{Al}$ and Si decreases insulation efficiency decreases with respect to decomposition. This is clear where the remaining weight for sample 16 insulation composition is $10.23 \%$ of the total insulation weight while for sample (20) insulation composition is $7.515 \%$ of the total insulation weight

\section{Ablation}

For ablation resistance of sample (5), the resultant ablation rate $(0.015 \mathrm{~mm} / \mathrm{sec})$ which corresponds to KP with $20 \mathrm{Phr}$ content is outstanding for rocket motor insulation (as compared to the current rate of 0.09 to $0.2 \mathrm{~mm} / \mathrm{sec}$ ). This is due to the KP content which itself has very high ablation resistance and stability up to $1450{ }^{\circ} \mathrm{C}$. The temperature at the back of the ablation test sample after 60 seconds $\left(79^{\circ} \mathrm{C}\right)$ indicates that the insulation which contains $\mathrm{KP}$ is outstanding thermal insulation material.

For ablation resistance of sample (8), the resultant ablation rate $(0.012 \mathrm{~mm} / \mathrm{sec})$ which corresponds to sample $8(10 \mathrm{Phr} \mathrm{KP}+10 \mathrm{Phr} \mathrm{Al})$ is outstanding for rocket motor insulation (as compared to the current rate of 0.09 to $0.2 \mathrm{~mm} / \mathrm{sec}$ ). This is due to the Al content which itself has very high ablation resistance and stability up to $2000{ }^{\circ} \mathrm{C}$. The temperature at the back of the ablation test sample after 60 seconds $\left(75^{\circ} \mathrm{C}\right)$ indicates that the insulation which contains $(\mathrm{KP}+\mathrm{Al})$ is outstanding thermal insulation material.

For ablation resistance of sample (S13), the resultant ablation rate $(0.013 \mathrm{~mm} / \mathrm{sec})$ which corresponds to sample $\mathrm{S} 13$ (10 Phr KP $+10 \mathrm{Phr} \mathrm{Si}$ ) is outstanding for rocket motor insulation (as compared to the current rate of 0.09 to $0.2 \mathrm{~mm} / \mathrm{sec}$ ). This is due to the Si content which itself has very high ablation resistance and stability up to $1665{ }^{\circ} \mathrm{C}$. The temperature at the back of the ablation test sample after 60 seconds $\left(70{ }^{\circ} \mathrm{C}\right)$ indicates that the insulation which contains $(\mathrm{KP}+\mathrm{Si})$ is outstanding thermal insulation material. 
For ablation resistance of sample (17), the resultant ablation rate $(0.010 \mathrm{~mm} / \mathrm{sec})$ which corresponds to sample $17(10 \mathrm{Phr} \mathrm{KP}+5 \mathrm{Phr} \mathrm{Al}+5 \mathrm{Phr} \mathrm{Si})$ is outstanding for rocket motor insulation (as compared to the current rate of 0.09 to $0.2 \mathrm{~mm} / \mathrm{sec}$ ). This is due to the presence of the three fillers $(\mathrm{KP}+\mathrm{Al}+\mathrm{Si})$. The temperature at the back of the ablation test sample after 60 seconds $\left(60^{\circ} \mathrm{C}\right)$ indicates that the insulation which contains the three fillers is the best in outstanding thermal insulation material.

\section{CONCLUSION}

For application for solid rocket motor insulation, Reinforcement of EPDM with KP improves the performance of the material with respect to mechanical properties and thermal properties (thermal conductivity) while not improving well the performance with respect to ablation resistance.

Using hybrid reinforcement content $(\mathrm{KP}+\mathrm{Al}+\mathrm{Si})$ inside EPDM improves the performance of EPDM with respect to mechanical properties, thermal properties, ablation resistance and decomposition resistance. The best volume fraction which gives the best performance of the insulation material is $10 \mathrm{Phr} \mathrm{KP}+5 \mathrm{Phr} \mathrm{Al}+5 \mathrm{Phr} \mathrm{Si}$.

\section{REFERENCES}

[1] Sutton, G.P. Rocket propulsion elements: An introduction to engineering of rockets. John Wiley, New York, pp. 444-46, (1992).

[2] Wang Zheng, Yongqiang Hu, Solid Rocket Motor, $1^{\text {st }}$ ed., Astronautics industry Press, Beijing, pp. 229-236, (1993).

[3] Tauzia, Jean-Michel. Thermal insulations, liners and inhibitors. In Solid rocket propulsion technology, edited by Alain Davenas, Pergamon Press, NewYork, pp. 553-83, (1993).

[4] C.M. Bhuvaneswari, M.S. Sureshkumer, S.D. Kakade, and Monaj Gupta. "Ethylene propylene rubber as a futuristic elastomer for insulation of solid rocket motor".Defence science journal, Vol 56, No.3, pp.309-320, (2006).

[5] Guillot, David. G. Novel, US Patent no 6787586, 'EPDM rocket motor insulation, (2004).

[6] Roberto Isopi, Eros Pittarelli, Antonio Sebasta. "Development of low density insulators for space motors". SNIA Viscosa, Space and defence Division Via Sicilia 162, Rome, Italy, (1979).

[7] R. E. Morgan, A. S. Prince, and S. A. Selvidge, and J. Phelps, C. L. Martin,T. W. Lawrence. "Non - asbestos insulation testing using a plasma torch", (2000).

[8] Guillot, David. G. Novel, US Patent no 5498649, 'Low density thermoplastic elastomeric insulation for rocket motors' (1996).

[9] Guillot, David. G. Novel, US Patent no 5399599, 'Thermoplastic elastomeric internal insulation for rocket motors for low temperature applications, (1995).

[10] A. J. Kinloch and R. J. Young, Behavior of polymers, Elsevier Science Publishers, Ltd., London, (1983).

[11] Blow, C.M., Rubber chemistry and technology. Butterworths, London, pp. 102-03, (1971).

[12] Herring, Liles G. Elastomeric insulating materials for rocket motors. US Patent No. 4,501,841, (1985).

[13] Coran, A.Y. In Science and technology of rubber, edited by James E. Mark, Burak Erman and Frederick R. Eirich. Academic Press, New York, pp. 339-346, (1994). 
[14] Barbin, W.W. \& Rodgers, M.B. Science and technology of rubber, edited by James E Mark, Burak Erman and Frederick R. Eirich. Academic Press, New York, pp. 437, (1994).

[15] Mangaraj, Duryodhan. Rubb. Chem. Technol, 75, 365-68, (2002).

[16] Brydson, J.A. In Rubber chemistry. Applied Science Publishers, London, UK, p. 323, (1978).

[17] Channel prime alliance, Dupont Company, Ethylene Propylene Diene polymers, Technical guide for polymers, (2004).

[18] Harry, S.Katz \& John, V.Milewski. In Handbook of fillers and reinforcements for plastics. Van Nostrand Reinhold Co, New York, pp.136-160, (1978).

[19] Dupont advanced fibers systems, Technical guide for KEVLAR, USA, (2005).

[20] Mathew S. Bell, William F. S. Tam. "ASRM case insulation design and development. Composite structure laboratory". NASA -CR-191947, Aerojet general corporation, (1992).

[21] Yalin Guo, Guozheming Qiu, Aihua Liu. "Study of a liquid insulation for the solid rocket motor". Department of applied chemistry, school of science, Northwestern Polytechnical University, Xian, Shaanxi 710072, China, Xian aerospace composites research institute, China, (2006).

[22] D. Sanschagrin and G. Couture .'Development of an asbestos free insulant for rocket motors".Defence research establishment Valcartier, 2459, Pie IX blvd. , north (P.O. box 8800) Courcelette, Quebec,Canada G0A 1R0, (1996).

[23] Douglas B. Cook and Frederick M. Perkins. "Assessment of EPDM elastomer change using the thermal flash method -calibration studies". Thiokol Corporation, Brigham city, Utah, (1993).

[24] E. A. Turi Ed. 'Thermal characterization of polymeric materials' Academic Press, New York, (1981).

[25] Kole, S.; Chaki, T.K.; Bhowmick, Anil K. \& Tripathy, D.K. Polym. Degrad. Stab., 1 , 109-16, (1996).

[26] F. Cauty, C. Erades and J. C. Godon. "Experimental study of the degradation of an internal thermal insulator". Office national d'etudes et de recheches aerospatials, Chatillon, France, (2000). 
Table (1) prepared samples formulations (PHR)

\begin{tabular}{|c|c|c|c|c|c|c|c|c|}
\hline $\begin{array}{c}\text { Comp. } \\
\text { Samples }\end{array}$ & EPDM & D & AT & PCA & KP & Al & Si & As \\
\hline S1 & 100 & 40 & 20 & 3 & 12 & - & - & - \\
\hline S2 & 100 & 40 & 20 & 3 & 14 & - & - & - \\
\hline S3 & 100 & 40 & 20 & 3 & 16 & - & - & - \\
\hline S4 & 100 & 40 & 20 & 3 & 18 & - & - & - \\
\hline S5 & 100 & 40 & 20 & 3 & 20 & - & - & - \\
\hline S6 & 100 & 40 & 20 & 3 & 14 & 6 & - & - \\
\hline S7 & 100 & 40 & 20 & 3 & 12 & 8 & - & - \\
\hline S8 & 100 & 40 & 20 & 3 & 10 & 10 & - & - \\
\hline S9 & 100 & 40 & 20 & 3 & 8 & 12 & - & - \\
\hline S10 & 100 & 40 & 20 & 3 & 6 & 14 & - & - \\
\hline S11 & 100 & 40 & 20 & 3 & 14 & - & 6 & - \\
\hline S12 & 100 & 40 & 20 & 3 & 12 & - & 8 & - \\
\hline S13 & 100 & 40 & 20 & 3 & 10 & - & 10 & - \\
\hline S14 & 100 & 40 & 20 & 3 & 8 & - & 12 & - \\
\hline S15 & 100 & 40 & 20 & 3 & 6 & - & 14 & - \\
\hline S16 & 100 & 40 & 20 & 3 & 8 & 6 & 6 & - \\
\hline S17 & 100 & 40 & 20 & 3 & 10 & 5 & 5 & - \\
\hline S18 & 100 & 40 & 20 & 3 & 12 & 4 & 4 & - \\
\hline S19 & 100 & 40 & 20 & 3 & 14 & 3 & 3 & - \\
\hline S20 & 100 & 40 & 20 & 3 & 16 & 2 & 2 & - \\
\hline S21 & 100 & 40 & 20 & 3 & - & - & - & 30 \\
\hline Reference & 100 & & & & & - \\
\hline & & & & & & - \\
\hline
\end{tabular}




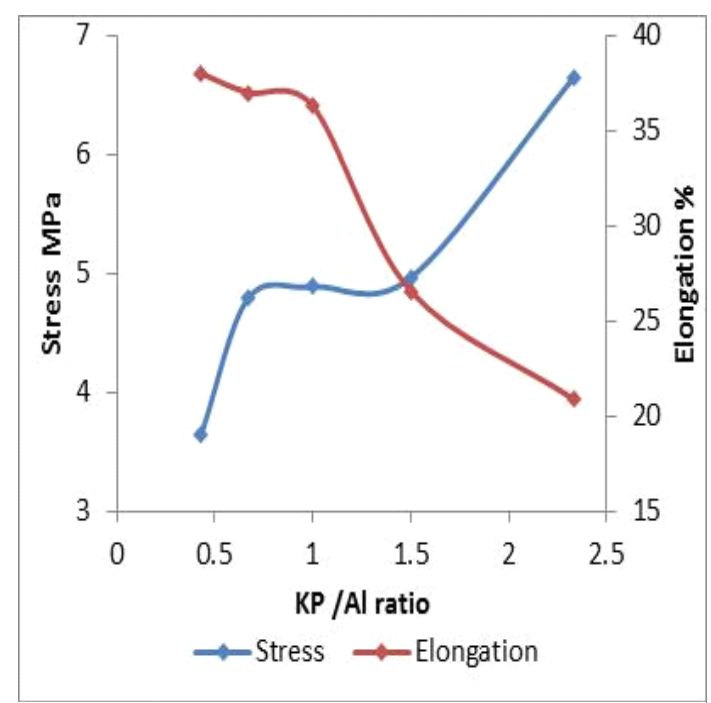

Fig (1) Tensile Strength \& Elongation as a function of KP Phr content

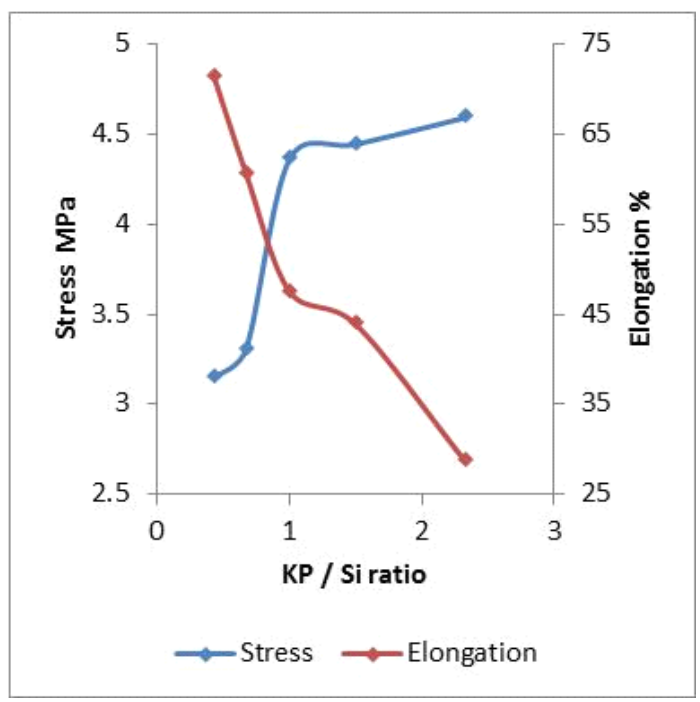

Fig (3) Tensile Strength \& Elongation as a function of $\mathrm{KP}$ and $\mathrm{Si}$

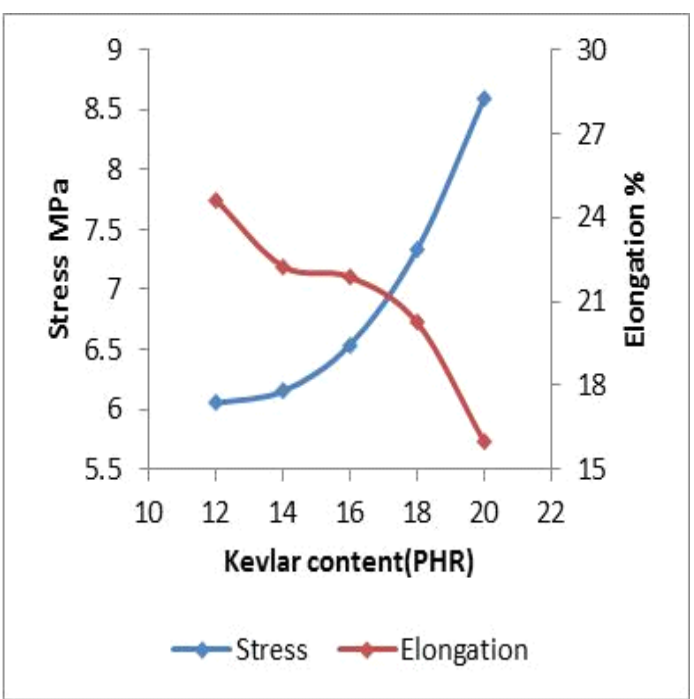

Fig (2) Tensile Strength \& Elongation as a function of $\mathrm{KP}$ and $\mathrm{Al}$

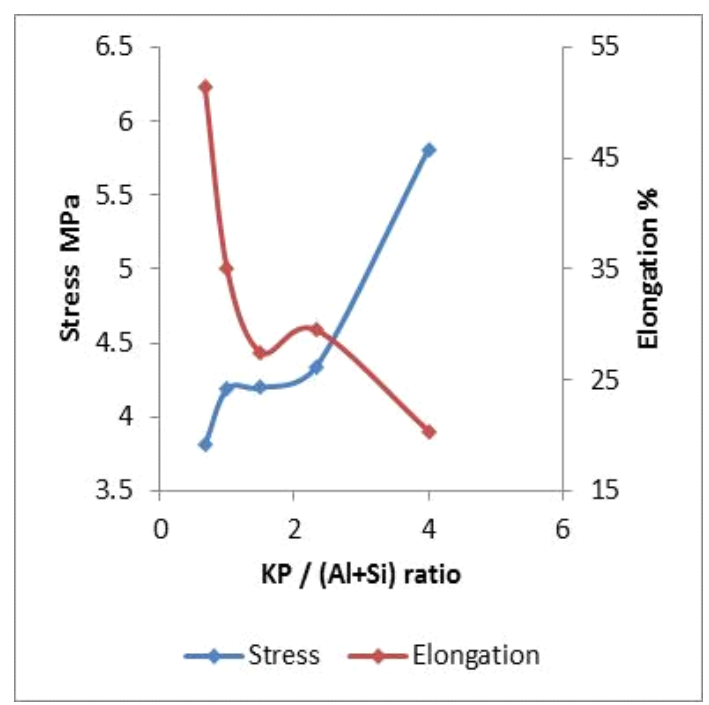

Fig (4) Tensile Strength \& Elongation as a function of $\mathrm{KP}$ and $\mathrm{Al}$ and $\mathrm{Si}$ 


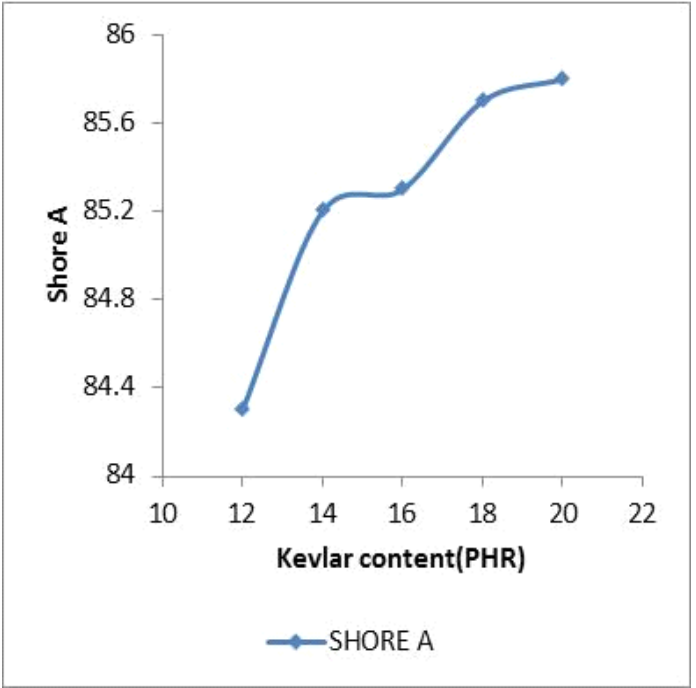

Fig (5) Hardness as a function of KP Phr content

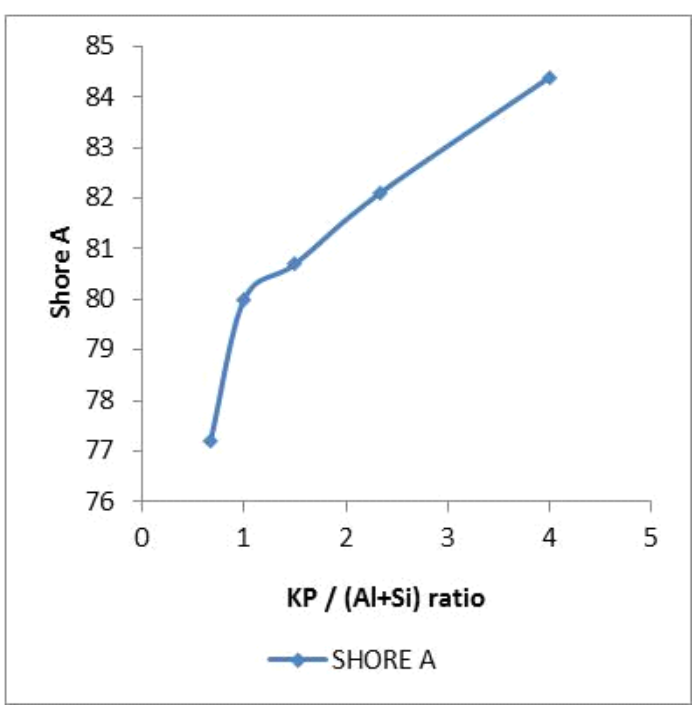

Fig (7) Hardness as a function of $\mathrm{KP}$ and $\mathrm{Si}$

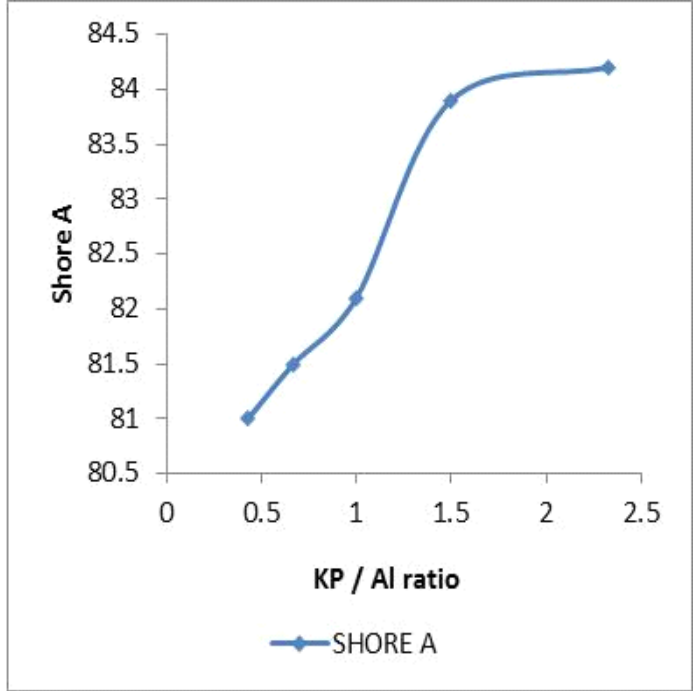

Fig (6) Hardness as a function of KP and Al

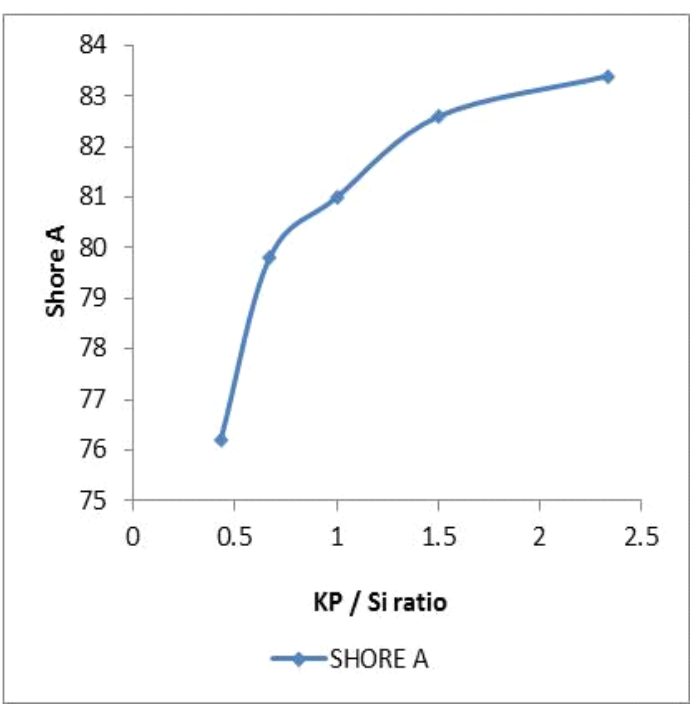

Fig (8) Hardness as a function $\mathrm{KP}$ and $\mathrm{Al}$ and $\mathrm{Si}$ 


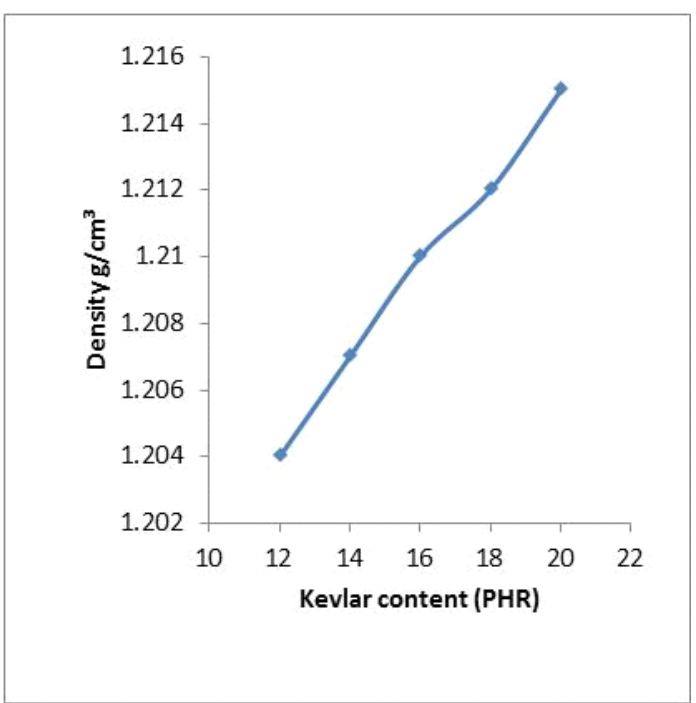

Fig (9) Density as a function of KP Phr content

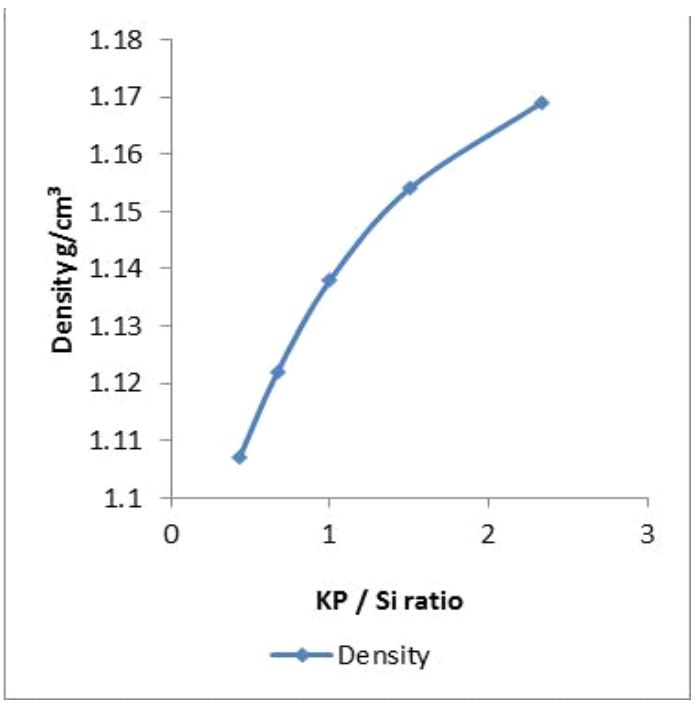

Fig (11) Density as a function of $\mathrm{KP}$ and $\mathrm{Si}$

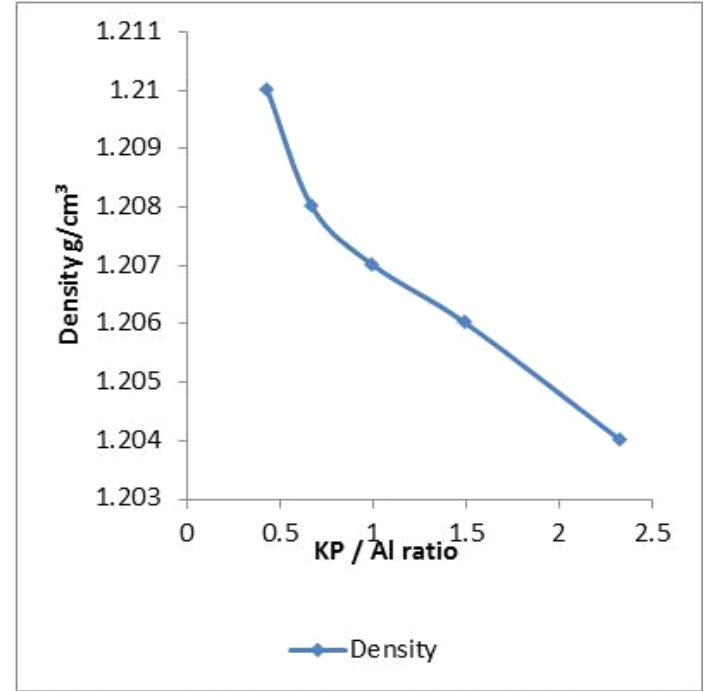

Fig (10) Density as a function of KP and Al

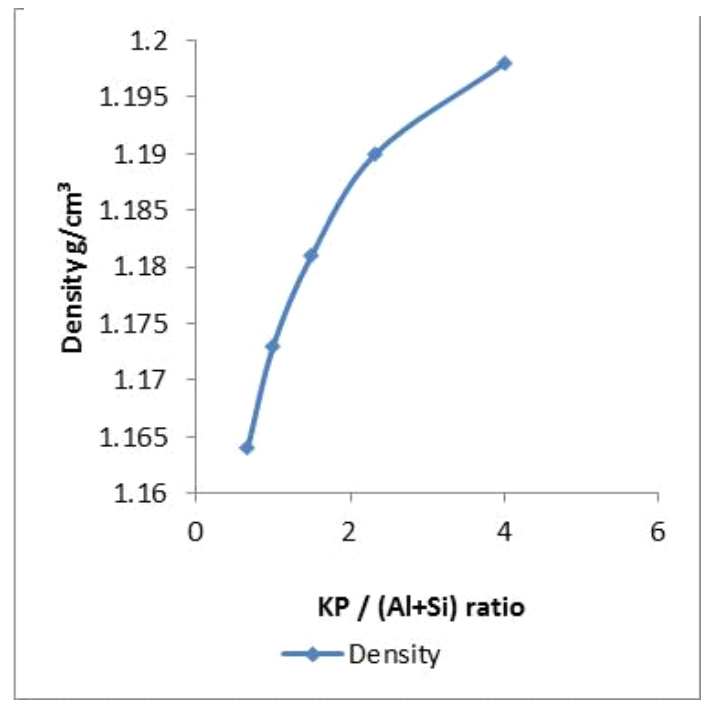

Fig (12) Density as a function KP and $\mathrm{Al}$ and $\mathrm{Si}$ 


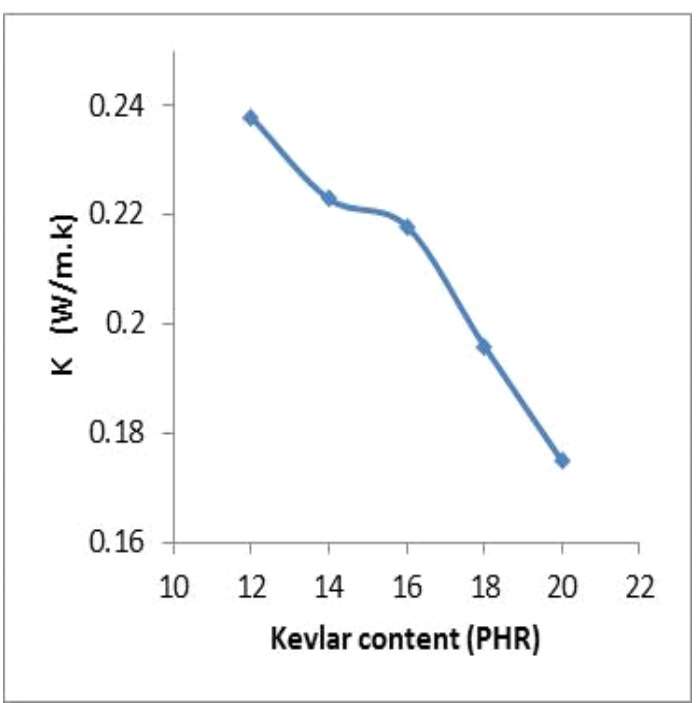

Fig (13) Thermal conductivity as a function of KP Phr content

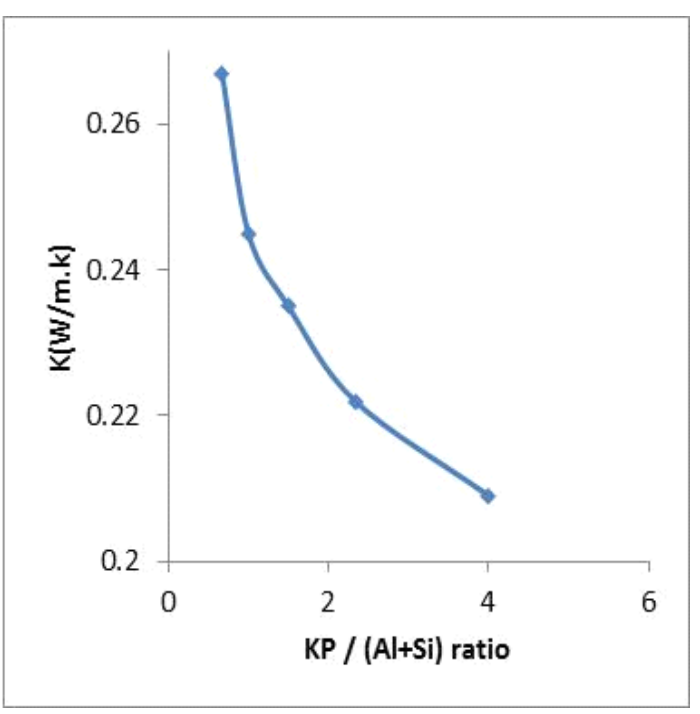

Fig (15) Thermal conductivity as a function of KP and $\mathrm{Si}$

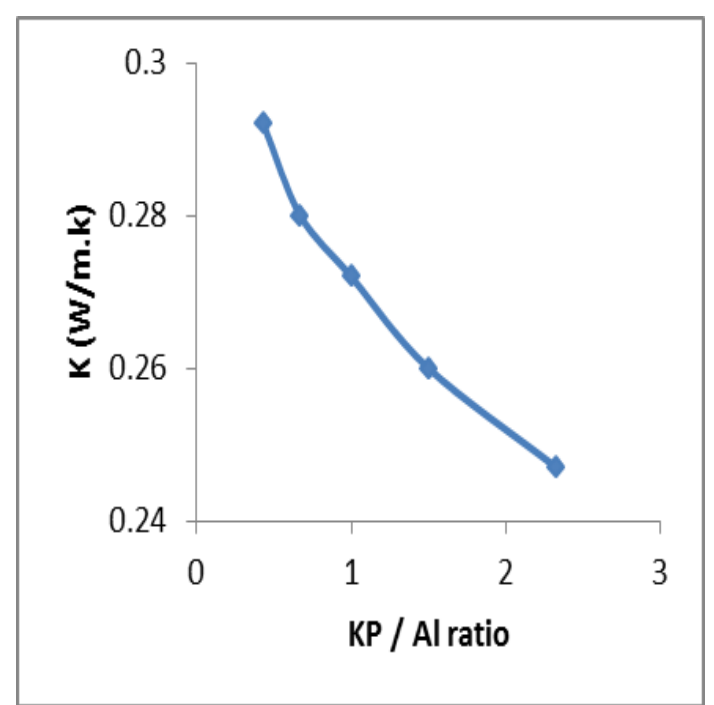

Fig (14) Thermal conductivity as a function of KP and $\mathrm{Al}$

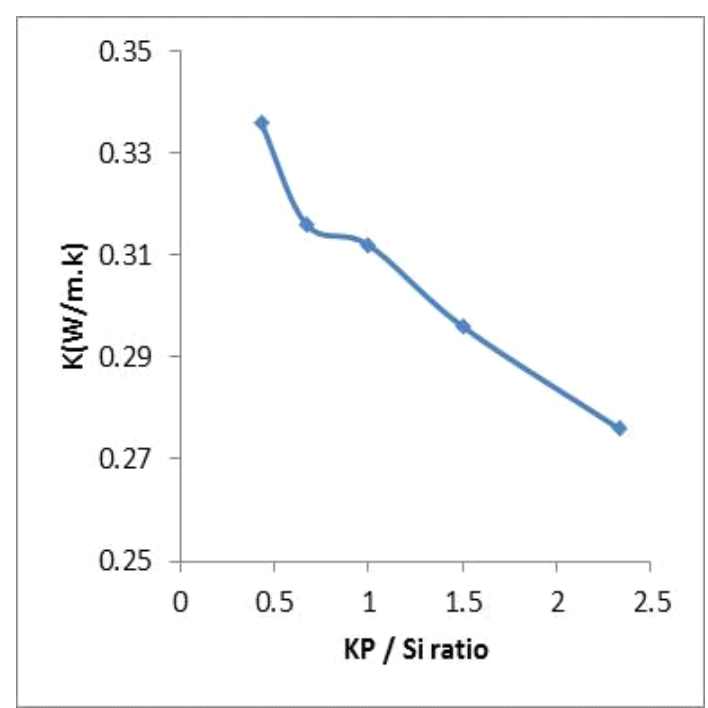

Fig (16) Thermal conductivity as a function of KP and $\mathrm{Al}$ and $\mathrm{Si}$

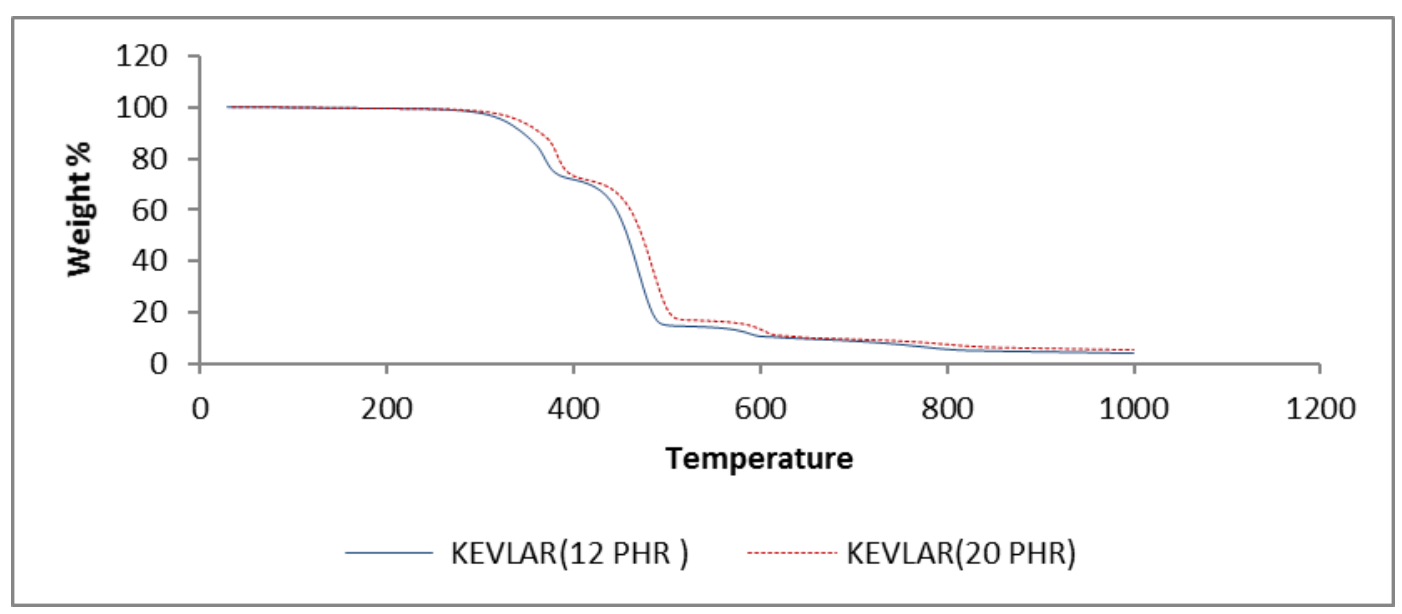

Fig (17) TGA curves for insulation compositions (1), (5) 


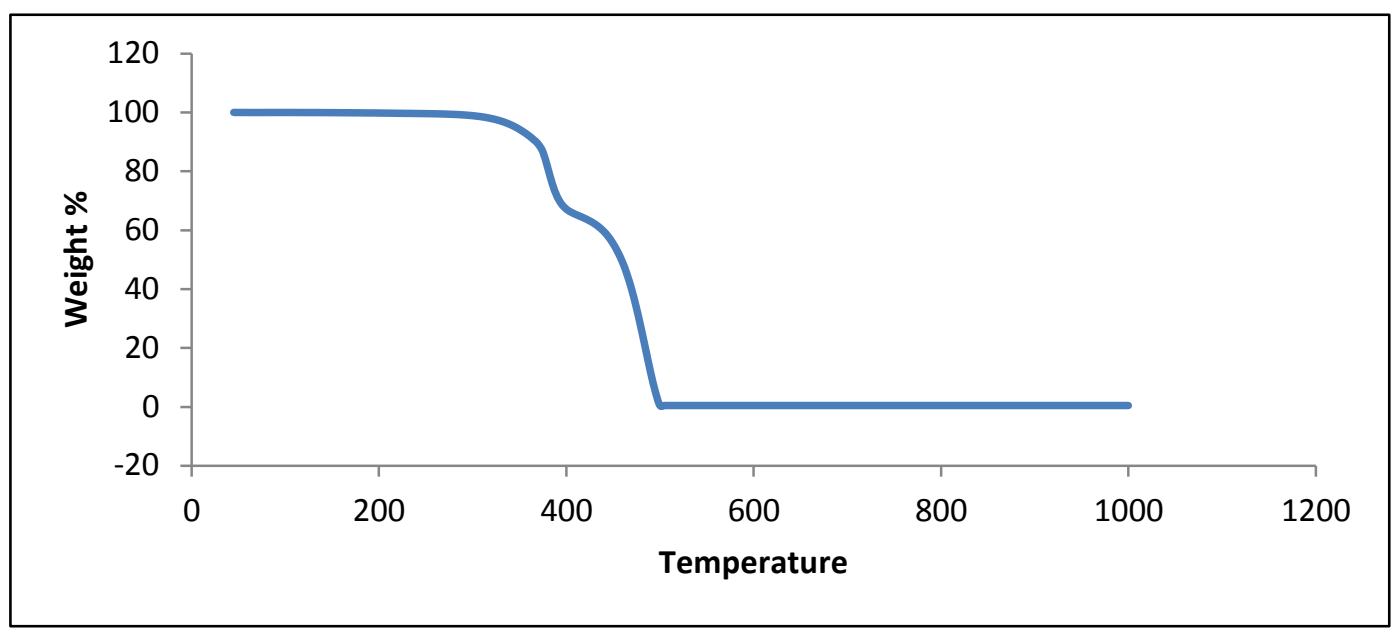

Fig (18) TGA curve for unloaded EPDM

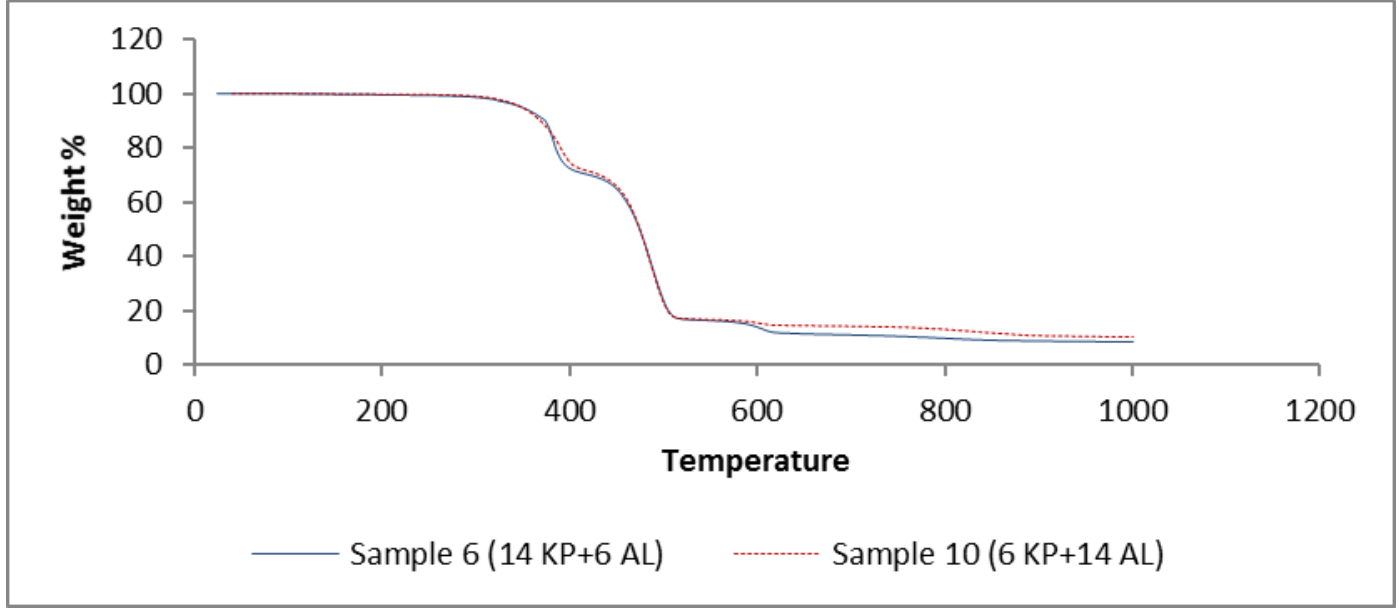

Fig (19) TGA curves for insulation compositions (6) , (10)

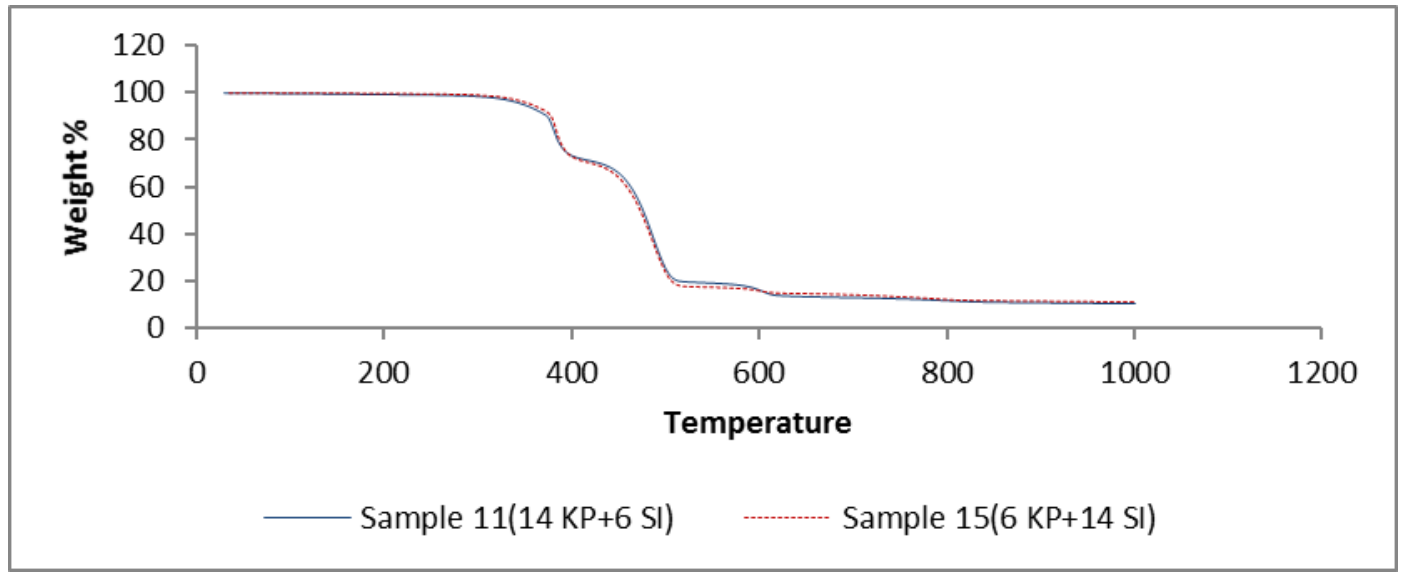

Fig (20) TGA curves for insulation compositions (11) , (15) 


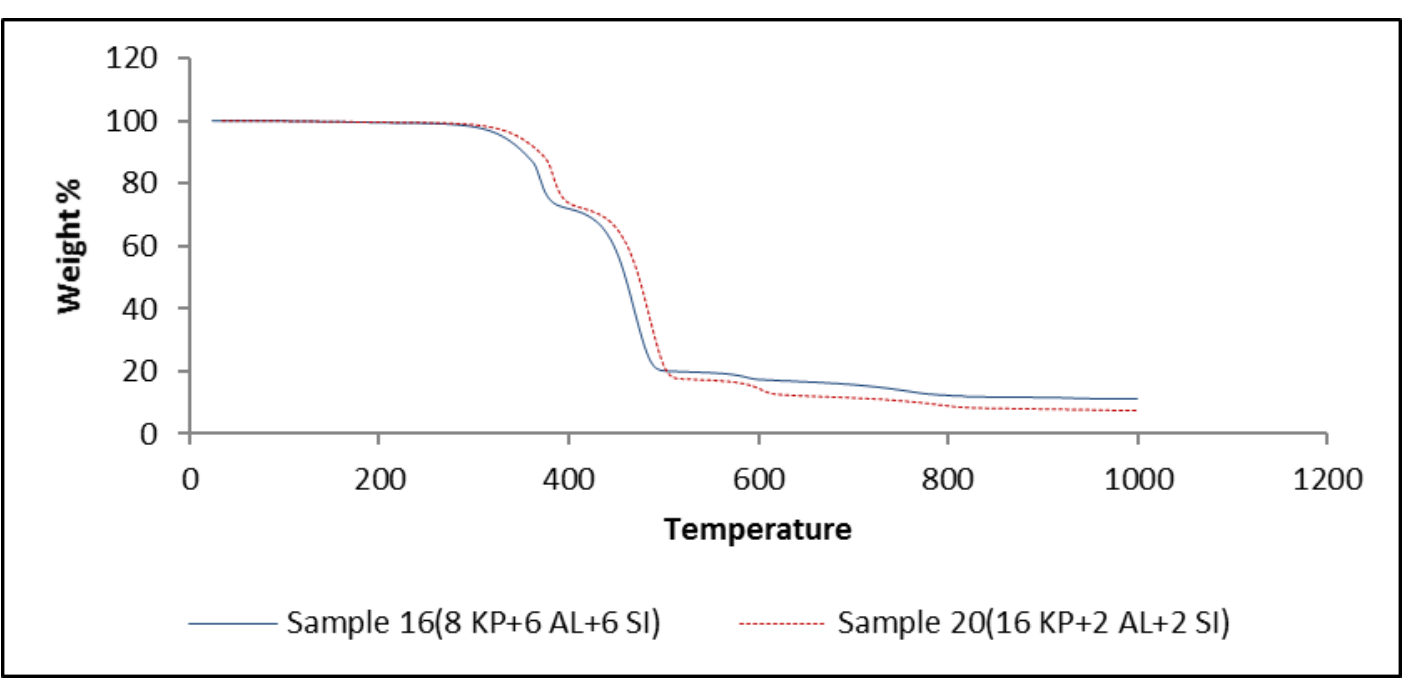

Fig (21) TGA curves for insulation compositions (16), (20) 